\title{
The Effects of Deep Breathing on Blood Pressure Reduction in Elderly Hypertensive Patients at a Retirement Home in Surabaya
}

\author{
Moch. Chaerudin ${ }^{1}$, Elida Ulfiana ${ }^{2}$, Erna Dwi Wahyuni ${ }^{2}$ \\ ${ }^{1}$ Student in Faculty of Nursing, Universitas Airlangga Surabaya, 60115, Indonesia, \\ ${ }^{2}$ Lecturer Faculty of Nursing, Universitas Airlangga Surabaya, 60115, Indonesia
}

\begin{abstract}
Introduction: The hypertension incidences in the elderly does not only cause stroke but also an increase in the mortality rate. The elderly who suffer from hypertension require further therapy to lower their blood pressure levels. One of the self-therapies that nurses can provide to hypertensive patients is deep breathing therapy. This study aims to determine the effects of deep breathing therapy in the elderly with hypertension.

Method: This study employed a quasi-experimental research design with two groups of pretest-posttest design. A total of 12 research samples were divided into two groups: the treatment group and the control group, each group consisted of six respondents. The research instruments utilized were a questionnaire, SOP (Standard Operating Procedure) of breathing techniques, blood pressure measurement tools (sphygmomanometer and stethoscope) and observation sheets on blood pressure measurement. The data were analyzed using paired t-test and independent t-test.
\end{abstract}

Results: All of the respondents in the study were women aged 55 years old or older. The mean value of systolic blood pressure before being given the intervention was $158.33 \mathrm{mmHg}$ in the treatment group and $157.69 \mathrm{mmHg}$ in the control group. The analysis with an Independent t-test between the control group and the treatment group indicated $\mathbf{p}=\mathbf{0 . 0 0 2}(\boldsymbol{\alpha}<\mathbf{0 . 0 5})$ as the difference in systolic blood pressure between the two groups. The treatment group experienced a drop in blood pressure by $10-30 \mathrm{mmHg}$.

Conclusion: Deep breathing therapy effectively reduces blood pressure in the elderly with hypertension by consistent interventions for seven consecutive days.

Keywords: Deep breathing intervention, elderly, isolated hypertension.

\section{Introduction}

The elderly experience the aging process that affects their physical and mental changes. Therefore, they have a higher risk of hypertension with the prognosis for stroke by $36 \%$ and an increase in the number of deaths by $14 \%{ }^{1}$.

\section{Corresponding Author:}

Elida Ulfiana

Lecturer Faculty of Nursing, Universitas Airlangga

Surabaya, 60115, Indonesia

e-mail: elidaulfiana@yahoo.com
Hypertension is a significant risk factor of cardiovascular morbidity and mortality, especially in the elderly. Such chronic disease frequently occurs without symptoms, thus requiring optimal control ${ }^{2}$. Hypertension in the elderly can occur due to increased sodium sensitivity, isolated systolic hypertension with arterial stiffness and endothelial dysfunction that increase with age ${ }^{3}$.

Men and women older than 55 years old highly at risk of suffering from hypertension, with a prevalence of $93 \%$ at approximately 80 years old ${ }^{2}$. The hypertension incidences in the elderly living in rural areas are very high, with a prevalence of $40.5 \%$, where $39.2 \%$ occur 
in men and $40.8 \%$ in women ${ }^{4}$. The Agency of Health Research and Development report in 2011 confirmed that the cause of death in 15 districts/cities in the elderly group was hypertension, with $4.4 \%$ of deaths at $<65$ years old and $4.6 \%$ at $>65$ years old ${ }^{5}$.

The preliminary studies conducted at Hargodedali Retirement Home, Indonesia, reported that 20 out of 51 elderly patients (39.2\%) suffered from hypertension. Hypertension incidences in Hargodedali Retirement Home were recorded as the highest compared to other places. The attempts made to lower blood pressure, including pharmacological therapy, green banana and green tea consumption, as well as exercise, for the elderly every Monday, were still not optimal.

Hypertension that generally occurs in the elderly requires further therapy, which is a treatment that not only decreases the mortality rate but also reduces stroke incidences ${ }^{6,7}$. The purpose of treating patients with isolated hypertension is to lower their blood pressure to the normal level while hypertension management in the elderly can be performed by pharmacological and nonpharmacological techniques ${ }^{8}$.

Deep breathing techniques are part of nursing interventions that aim to provide various benefits. The effects of deep breathing techniques include pulse decrease, muscle tension decrease and metabolic rate decrease. Meanwhile, the techniques increase global awareness, peace and wellness feelings and relaxed alertness period ${ }^{9}$. The advantage of deep breathing exercises is that it can be performed at anytime and anywhere. Furthermore, the techniques are very easy to perform independently by the patient without a medium to relax tense muscles ${ }^{8}$.

The functional consequences theory elaborates that age is related to changes and risk factors. Without the intervention, the functional consequences will be negative. Otherwise, with the intervention, the functional consequences will be positive. The role of gerontological nursing is to identify factors that cause negative functional consequences and initiate interventions to foster positive functional consequences. In accordance with this theory, the elderly hypertensive patients who perform deep breathing techniques can change negative consequences in the form of blood pressure increase into the positive consequences in the form of blood pressure decrease ${ }^{10}$. This study aims to determine the effect of deep breathing on reducing blood pressure in the elderly with hypertension.

\section{Method}

This study employed a quasi-experimental research design with two groups of pretest-posttest design. The research site was at Hargodedali Retirement Home, Surabaya, Indonesia. In this design, groups that fulfilled the inclusion criteria were observed for their blood pressure. There were inclusion criteria set by the researchers, i.e., the elderly with normal hearing, a patient who received hypertension treatment and were willing to be the respondents. Furthermore, the elderly would be intervened using deep breathing techniques. The intervention was performed for seven days, while the respondents' blood pressure was observed before and after the treatment.

The sampling techniques employed in this study were non-probability sampling with a purposive sampling type. The samples in the control group consisted of 6 respondents, while the treatment group, which performed deep breathing techniques, were six respondents. The total samples in this study were 12 respondents.

The determination of the selected samples consisted of isolated hypertensive patients who fulfilled the established inclusion and exclusion criteria. After specifying the sample size of the study (12 elderly), then the data collection and matching were carried out, i.e., the process of adjusting confounding variables between 2 groups (6 elderly in each group), thus the confounding variables were divided equally.

The instrument utilized in this study was questionnaires related to demographic data, SOP (Standard Operating Procedures) for deep breathing techniques and observation sheets for blood pressure measurement, sphygmomanometer and stethoscope. The observation sheet in this study contained a format consisting of respondents codes, age, sex and blood pressure before and after deep breathing exercises in the treatment and control groups designed by the researcher.

The data analysis was processed based on existing data by using tables and statistical tests. The variables tested were the pretest and posttest of systolic blood pressure as well as the comparison results between the treatment group and the control group. The interval data for blood pressure measurement using paired t-test were used to compare the interval data of pre and posttreatment tests. Meanwhile, the independent t-test was employed to compare the interval data of the treatment group and the control group. 


\section{Results}

The first research results were related to the demographic data of the elderly respondents involved.
Twelve respondents who were divided into two groups were recorded for their general information, including age, sex, smoking history, family history of hypertension, their savoury tooth and regular exercise.

Table 1 Characteristics Respondents

\begin{tabular}{|c|c|c|c|c|c|}
\hline \multirow{2}{*}{ No. } & \multirow{2}{*}{ Characteristics } & \multicolumn{2}{|c|}{ Treatment } & \multicolumn{2}{|c|}{ Control } \\
\hline & & $\mathbf{N}$ & $\%$ & $\mathbf{N}$ & $\%$ \\
\hline \multirow[t]{4}{*}{1} & \multicolumn{5}{|l|}{ Gender } \\
\hline & Male & 0 & 0 & 0 & 0 \\
\hline & Female & 6 & 100 & 6 & 100 \\
\hline & Total & 6 & 100 & 6 & 100 \\
\hline \multirow[t]{4}{*}{2} & \multicolumn{5}{|l|}{ Age } \\
\hline & $55-70$ years old & 2 & 33.3 & 2 & 33.3 \\
\hline & $70-85$ years old & 4 & 66.7 & 4 & 66.7 \\
\hline & Total & 6 & 100 & 20 & 100 \\
\hline \multirow[t]{4}{*}{3} & \multicolumn{5}{|l|}{ Smoking status } \\
\hline & Never smoked & 6 & 100 & 6 & 100 \\
\hline & Elementary school & 0 & 0 & 0 & 0 \\
\hline & Total & 6 & 100 & 6 & 100 \\
\hline \multirow[t]{4}{*}{4} & Family History of Hypertension & & & & \\
\hline & Yes & 2 & 33.3 & 2 & 33.3 \\
\hline & No & 4 & 66.7 & 4 & 66.7 \\
\hline & Total & 6 & 100 & 20 & 100 \\
\hline \multirow[t]{4}{*}{5} & Savoury Tooth & & & & \\
\hline & Yes & 0 & 0 & 0 & 0 \\
\hline & No & 6 & 100 & 6 & 100 \\
\hline & Total & 6 & 100 & 6 & 100 \\
\hline \multirow[t]{4}{*}{6} & Regular exercise & & & & \\
\hline & Gymnastics & 6 & 100 & 6 & 100 \\
\hline & No regular exercise & 0 & 0 & 0 & 0 \\
\hline & Total & 6 & 100 & 6 & 100 \\
\hline
\end{tabular}

Systolic Blood Pressure Before and After the Intervention: The respondents' characteristics based on age suggested that most of the respondents in each group were 70-85 years old, i.e., 4 people in the intervention group (66.7\%) and 4 people in the control group (66.7\%). The respondents' characteristics by gender indicated that all respondents in each group were women. The respondents' characteristics based on smoking status denoted that all respondents in each group had never smoked.

In addition, the respondents' characteristics based on a family history of hypertension suggested that most of the respondents in each group had a family member with hypertension, i.e., there were 2 people in the intervention group (33.3\%) and 2 people in control group (33.3\%). Regarding the respondents' characteristics based on savoury tooth, all of the respondents in each group did not like the salty taste. This data was obtained from interviews related to demographic data. Furthermore, the nutrition fulfillment at the elderly nursing home was adjusted to the type of illness that the respondent suffered. Thus, the nutrients fulfillment was homogeneous. 
Table 2. The mean differences in systolic blood pressure before and after the intervention in the treatment and control groups

\begin{tabular}{|c|c|c|c|c|c|c|}
\hline \multirow{2}{*}{ Respondents } & \multicolumn{3}{|c|}{ Treatment group } & \multicolumn{3}{|c|}{ Control group } \\
\hline & Pre & Post & Interval & Pre & Post & Interval \\
\hline 1 & 150 & 140 & -10 & 150 & 150 & 0 \\
\hline 2 & 160 & 140 & -20 & 160 & 160 & 0 \\
\hline 3 & 170 & 150 & -20 & 170 & 170 & 0 \\
\hline 4 & 160 & 140 & -20 & 150 & 160 & +10 \\
\hline 5 & 140 & 130 & -10 & 140 & 150 & +10 \\
\hline 6 & 170 & 140 & -30 & 170 & 170 & 0 \\
\hline Rerata & 158.33 & 140.00 & 18.33 & 157.69 & 160.00 & 3.3 \\
\hline Deviation Standard & 11.60 & 6.32 & 7.52 & 12.31 & 8.99 & 5.16 \\
\hline Paired Test & \multicolumn{3}{|c|}{0.002} & \multicolumn{3}{|c|}{0.175} \\
\hline \multicolumn{7}{|c|}{ Independent t-test 0.002} \\
\hline
\end{tabular}

Systolic Blood Pressure Before and After the Intervention: The mean in systolic blood pressure is different before and after intervention in each group. It was observed that the mean value of systolic blood pressure before intervention in the treatment group was $158.33 \mathrm{mmHg}$ and in the control group was 157.69 $\mathrm{mmHg}$. After the intervention was performed with 21 times of deep breathing exercises for one week, the mean value of systolic blood pressure in the treatment group reached $140.00 \mathrm{mmHg}$.

The results of the advanced statistical analysis utilizing the Independent t-test between the control group and the treatment group obtained $\mathbf{p}=\mathbf{0 . 0 0 2}(\boldsymbol{\alpha}<\mathbf{0 . 0 5})$. Therefore, it is concluded that there were differences in systolic blood pressure between the two groups. The preliminary data measurement (pretest) of blood pressure in the intervention group, with 6 hypertensive respondents indicated 2 people in stage 1 hypertension and 4 people in stage 2 hypertension. In the control group, it is observed that there were 3 people in stage 1 hypertension and 3 people in stage hypertension 2 .

The blood pressure results in the treatment group after provided with deep breathing exercises (posttest) also suggested that all respondents (6 people) tended to experience a decrease which changed the hypertension category, i.e., 1 respondent reached the prehypertension category $(120-139 \mathrm{mmHg}$ ) and 5 respondents reached the stage 1 hypertension category (140-159 $\mathrm{mmHg}$ ). On the other and, in the control group, there were 2 respondents reached stage 1 hypertension category and 4 respondents with stage 2 hypertension category $(\geq 160$ $\mathrm{mmHg}$ ).

\section{Discussion}

The critical factor causing hypertension is age. The older a person, the higher a person's blood pressure. That condition is related to changes in anatomical and physiological structures, especially of the cardiovascular system changes due to the aging process. It occurs because of a decrease inblood vessel elasticity, blood vessel stretching power and smooth muscle relaxation. The factors contributing to the thickening and stiffening of the endothelial blood vessels in the aging process include an increase in collagen and calcium and a decrease in elastin, calcification and fat deposits ${ }^{11}$.

All respondents in this study were female,so the case was similar to prior studies. In the prior study results, it was suggested that hypertension tended to occurred higher to women $(58.3 \%)$ than to men $(41.7 \%)$ after menopause ${ }^{12}$. It occurred higher to women because of the production of their sexual hormones changes during menopause, which cause an increase in blood pressure ${ }^{13}$. Women are greatly affected by several hormones that function to protect women from hypertension and its complications, including the thickening of blood vessels or atherosclerosis walls ${ }^{9}$

Thenext factor causing hypertension is due to diet food consumption, for example, unable to undertake a 
low-salt diet. The respondents consumed food according to the food served based on the nursing policy. There was a special diet menu as the treatment, so there were limits as a benchmark to monitor whether the respondents had performed a low salt diet appropriately and consistently. Sodium consumption can be a significant factor causing hypertension 14. The compliance of low calcium, potassium and magnesium diet contributed to lowering blood pressure ${ }^{14}$.

The treatment group had performed deep breathing techniques three times in one week for 7 days. In every 15 minutes of exercise, there was a decrease in systolic blood pressure by $140.00 \mathrm{mmHg}$. Therefore, there was a change regarding the hypertension category, which declined to stage 1 hypertension. Slow breathing frequency increases vascular vasodilation, which activates the Hering-Breuer reflex and then reduce the chemoreflex sensitivity and increase baroreflex ${ }^{15}$. The deep breath therapy is beneficial as tense muscles relaxation, metabolic rate decrease, feelings of peace and alertness improvement and lowering blood pressure ${ }^{8}$.

After 7 days of intervention, the mean of systolic blood pressure was the lowest in the deep breathing treatment group, which was $140 \mathrm{mmHg}$. Meanwhile, the control group reached $160 \mathrm{mmHg}$. The further analysis stated that the results obtained in both groups signifying systolic blood pressure decrease, which attributed to deep breathing exercises in the elderly with isolated hypertension. Deep breathing exercises in the form of slow breathing led to changes in breathing pattern intervals, which resulted in baroreflex efficiency increase. Eventually, the blood pressure can be lowered ${ }^{16}$.

The role of gerontological nursing was to identify the factors causing negative functional consequences after initial deep breathing intervention that would produce positive functional consequences. Gerontological nursing aims to make the elderly relaxed and comfortable. The slowed breathing frequency triggers a decrease in the impulse of the respiratory and cardiovascular system ${ }^{17}$. The respiratory and cardiovascular systems have the same regulatory mechanism. A change to one system will affect the other system functions. The deep breathing maximizes lung expansion during breathing. In addition, the breath-holding phase aims to maximize the oxygen diffusion in the lungs to acquire the oxygen better fulfillment for cellular metabolism in the elderly ${ }^{17}$. Slow breathing can reduce sympathetic nerve activity by increasing central inhibitory rhythm. Hence, it created comfort and relaxation ${ }^{18}$.

\section{Conclusion}

Deep breathing exercises and techniques effectively reduce blood pressure in the elderly with hypertension. It is corroborated by the difference in systolic blood pressure before and after the intervention in the elderly with isolated hypertension. Besides, it is also proved by a mean difference between the treatment and control groups. Breath control can reduce systolic blood pressure in the elderly with isolated hypertension by 3 times exercises a day and each exercise is performed in 15 minutes for 7 days.

Ethical Clearance: The present study fulfilled the ethical feasibility test at Universitas Airlangga with certificate number 260-KEPK.

Conflict of Interest: None declared

Source of Funding: This study is done with individual funding.

\section{Reference}

1. Bulpitt CJ, Beckett NS, Cooke J, Dumitrascu DL, Gil-Extremera B, Nachev C, et al. Results of the pilot study for the Hypertension in the Very Elderly Trial. Journal of Hypertension [Internet]. 2003;21(12). Available from: https://journals.lww. com/jhypertension/Fulltext/2003/12000/Results of_the_pilot_study_for_the_Hypertension_in.30. aspx

2. Lionakis N, Mendrinos D, Sanidas E, Favatas G, Georgopoulou M. Hypertension in the elderly. World journal of cardiology [Internet]. 2012/05/26. 2012 May 26;4(5):135-47. Available from: https:// www.ncbi.nlm.nih.gov/pubmed/22655162

3. Stokes GS. Management of hypertension in the elderly patient. Clinical interventions in aging [Internet]. 2009/10/12. 2009;4:379-89. Available from: https://www.ncbi.nlm.nih.gov/ pubmed/19851513

4. Chinnakali P, Mohan B, Upadhyay RP, Singh AK, Srivastava R, Yadav K. Hypertension in the elderly: prevalence and health seeking behavior. North American journal of medical sciences [Internet]. 2012 Nov;4(11):558-62. Available from: https:// www.ncbi.nlm.nih.gov/pubmed/23181226

5. Balitbang Kemenkes RI. Riset kesehatan dasar; RISKESDAS. Jakarta: Balitbang Kemenkes RI. 2013;2013:110-9. 
6. Musini VM, Tejani AM, Bassett K, Wright JM. Pharmacotherapy for hypertension in the elderly. Cochrane Database of Systematic Reviews. 2009;(4).

7. Perry H. Mitchell J, Davis BR, Price TR, Applegate WB, Fields WS, Guralnik JM, et al. Effect of Treating Isolated Systolic Hypertension on the Risk of Developing Various Types and Subtypes of StrokeThe Systolic Hypertension in the Elderly Program (SHEP). JAMA [Internet]. $2000 \mathrm{Jul}$ 26;284(4):465-71. Available from: https://dx.doi. org/10.1001/jama.284.4.465

8. Suzanne C, Brenda G, Janice L, Kerry H. Text book of medical surgical nursing. Philadelphia: Lippincott Williams \& Wilkins; 2008.

9. Potter PA, Perry AG. Fundamentals of nursing. 2004;

10. Miller CA. Nursing for wellness in older adults. Lippincott Williams \& Wilkins; 2018.

11. Prisant LM. Clinical trials of hypertension in the older patient. In: Hypertension in the Elderly. Springer; 2005. p. 91-115.

12. Kimura T, Yokoyama T, Matsumura Y, Yoshiike N, Date C, Muramatsu M, et al. NOS3 genotypedependent correlation between blood pressure and physical activity. Hypertension. 2003;41(2):35560.
13. Coylewright $\mathrm{M}$, Reckelhoff JF, Ouyang $\mathrm{P}$. Menopause and hypertension: an age-old debate. Hypertension. 2008;51(4):952-9.

14. LeMone P, Burke KM. Clinical handbook for medical-surgical nursing: critical thinking in client care. Prentice Hall; 2008.

15. Francis DP, Coats AJS, PonikowskiP. Chemoreflexbaroreflex interactions in cardiovascular disease. Sleep Apnea: Implications in cardiovascular and cerebrovascular disease. 2000;33-60.

16. Bernardi L, Porta C, Spicuzza L, Bellwon J, Spadacini G, Frey AW, et al. Slow breathing increases arterial baroreflex sensitivity in patients with chronic heart failure. Circulation. 2002;105(2):143-5.

17. Wang S-Z, Li S, Xu X-Y, Lin G-P, Shao L, Zhao Y, et al. Effect of slow abdominal breathing combined with biofeedback on blood pressure and heart rate variability in prehypertension. The Journal of Alternative and Complementary Medicine. 2010;16(10):1039-45.

18. Kaushik RM, Kaushik R, Mahajan SK, Rajesh V. Effects of mental relaxation and slow breathing in essential hypertension. Complementary Therapies in Medicine [Internet]. 2006;14(2):120-6. Available from: http://www.sciencedirect.com/ science/article/pii/S0965229905001482 